\title{
Biphasic anaphylaxis after use of foam polidocanol sclerotherapy
}

\section{Deniz Demir $\odot$, Nail Kahraman $\odot$, İbrahim Burak Şeker $\odot$, Arif Gücü®, Şenol Yavuz $\odot$, Mehmet Tuğrul Göncü®}

Department of Cardiovascular Surgey, University of Health Sciences, Bursa Yüksek Ihtisas Training and Research Hospital, Bursa, Turkey

\begin{abstract}
Polidocanol is a sclerogenic agent commonly used for the treatment of varicose veins. Common complications such as hyperpigmentation, telangiectasia matting on skin may be observed in relation with foam sclerotherapy. Complications such as deep vein thrombosis, stroke and tissue necrosis are rarely seen. Fatal complications such as anaphylaxis are seen very uncommonly. A 50-year-old female patient underwent polidocanol foam sclerotherapy for left leg reticular varicosity (CEAP 2-3). Our patient has experienced biphasic anaphylaxis, which was observed as two attacks following the foam sclerotherapy. Biphasic anaphylaxis complication after the foam sclerotherapy is not known, this presentation may even be the first condition experienced ever.
\end{abstract}

Keywords: Varicose vein, polidocanol, biphasic anaphylaxis

$\mathrm{P}$ olidocanol foam sclerotherapy (PFS) is currently used in the treatment of reticular and telangiectasic veins. Patients may commonly experience complications such as cutaneous hyperpigmentation, telangiectatic matting and migraines following the foam sclerotherapy. They may experience deep vein thrombosis, stroke, tissue necrosis rarely and anaphylaxis reactions uncommonly $[1,2]$.

It is notified in the literature that anaphylactic reactions emerging following the sclerotherapy are generally seen in the first 15 minutes [3]. The fact rending this case as interesting is the manifestation of anaphylactic reaction in late hours in two attack phases. We could not find the literature relevant in the post-PFS biphasic anaphylactic reaction cases. We have reported this case that was seen uncommonly and progressing different than common anaphylactic reaction.

\section{CASE PRESENTATION}

A 50-year-old female patient underwent PFS treatment for the reticular varicose veins (CEAP 2-3) [4] in her left leg. It was determined from the medical background of patient that she had no allergic condition before and that PFS to be performed for the first time. Policocanol 0.5\% (Aethoxysklerol ${ }^{\circledR}$ Hameln, Germany.) and $1 / 4$ air mixture is prepared by using Tessari method for the patient [5]. Approximately $8 \mathrm{cc}$ foam has been injected slowly in 10 minutes to 5-6 different reticular veins sections with $25 \mathrm{G}$ winged needle (Braun Venofix A Winged Infusion Set, Germany). Following the procedure, extremity was wrapped with elastic compression plaster. Patient has experienced dizziness and mild shortness of breath in 10 minutes following the PFS. Arterial tension was $80 / 60 \mathrm{mmHg}$. Patient had left the our outpatients' 
clinic with good clinical conditions after half an hour.

Approximately 3 hours after sclerotherapy, an anesthesiologist of another hospital reported on the phone that the patient was taken to intensive care unit because of tachycardia, severe shortness of breath, severe hypotension and shock. Patient was employed as operation room personnel in other hospital and the incident was occurred in the hospital. Therefore, first medical intervention was performed immediately in intensive care unit. During the consultation held with anesthesiologist, information was shared that the PFS was performed on the patient. It was understood that the patient had biphasic anaphylactic reaction in late period during her care in another medical center. Single dose $0.5 \mathrm{mg}$ epinephrine injection, isotonic serum and i.v. $8 \mathrm{mg}$ corticosteroid (dexamethasone) treatment was applied for the treatment of the patient. Patient was transferred from intensive care unit after one day treatment to service. Then the patient was discharged from the service at second day of the anaphylactic reaction.

\section{DISCUSSION}

Chronic venous disease (CVD) of the lower extremities is defined as a dysfunction in the venous system due to venous hypertension caused by valve insufficiency and / or obstruction in venous flow. CVD is a disease with high prevalence morbidity and chronicity. Surgery, medical therapy and sclerotherapy are some treatment options [11].

Polidocanol is commonly used for the treatment of reticular and telangiectasic varicose veins sclerotherapy. PFS commonly used for the treatment of varicosity with high efficiency and low side effect incidence. Severe anaphylaxis $(1 / 10000)$ due to the use of polidocanol used in liquid or foam form can be seen. Anaphylaxis reaction in patients may cause symptoms as advanced as respiratory distress, cardiac arrhythmia or cardiac arrest $[3,6]$. Anaphylaxis is a hypersensitivity reaction that rapidly develops and may result in death. An anaphylaxis reaction model may occur in the form of non-phase (monophasic) and biphasic (also known as delayed or late phase) [7].

Exposure to anaphylaxis reaction antigen occurs in 5-30 minutes through parenteral means and in first
2 hours through oral means. In some cases, a new attach may be developed in 2-24 hours following the complete recovery of initial attack. This condition is known as biphasic anaphylaxis. Biphasic anaphylaxis is seen on cases, where epinephrine treatment is delayed. Some studies have found a relationship between delayed epinephrine treatment and biphasic anaphylaxis $[7,8]$.

In our case, patient has experienced mild shortness of breath and hypotension in 10 minutes following the polidocanol injection. We have not encountered with any other finding in the examination. We have performed and monitored the patient for half an hour. In this period, shortness of breath has regressed and tension has reached normal levels. We have not considered the risk of anaphylaxis since there was no dramatic change in the condition of patient and symptoms have progressed mildly. We didn't do any treatment. However, approximately 3 hours later, via call doctor of another hospital in the same city has informed that the patient was admitted due to severe hypotension and dyspnea and tachycardia. It was understood from the information obtained from the patient that she did not come into contact with allergens in this period. It was found that the patient had a biphasic anaphylaxis reaction with the symptoms and findings.

Frequency of allergic reactions notified is around $0.6 \%$ following the sclerotherapy. Anaphylaxis reactions are uncommonly notified. In general, anaphylaxis reactions may occur due to hypersensitivity for any allergen. Currently, there is no method to identify the predisposed individuals and hence such adverse reactions are not preventable. However, patients implemented with multiple sclerosing agent may contain more risk of anaphylaxis. It is vitally important to implement epinephrine injection, liquid replacement and respiratory support for the emerging anaphylaxis [9].

Lee et al. [10] have notified that biphasic anaphylaxis are seen in the rate of $1 / 20$ in meta-analysis, where they have assessed anaphylaxis patients comprised of 4,114 patients. It is notified in this meta-analysis that it is not possible to predetermine biphasic anaphylaxis in practical means and that hypotension developed in patients may be related with biphasic anaphylaxis. They have not specified any 
concrete finding apart from that [10].

We believe that reason of failure to determine anaphylaxis reaction in the first phase is mild progression of symptoms and pain due to PFS procedure may be the reason for this condition. We have not performed epinephrine injection since we did not considered anaphylaxis in the first phase. We also believe that failure to implement epinephrine to the patient in the first phase has caused severe phase of biphasic anaphylaxis reaction. It must be considered that mild progression of first phase in biphasic anaphylaxis reaction may be related with possible anaphylaxis reaction even in rare conditions as occurred in our case. We believe that it may be beneficial to observe such patients for longer period. In the literature search we have conducted (MEDLINE, Google Scholar) we have not encountered with any literature study relating to content of "biphasic anaphylaxis, polidocanol". Post PFS anaphylaxis cases are rarely notified in the literature for the varicosity treatment $[3,9]$. However, biphasic anaphylaxis cases are very rare as in our case and this report may be the first one in the literature. We believe that the our case is significant in this aspect.

\section{CONCLUSION}

This case presented here may be a very rare clinical condition in literature. In our opinion, nonspecific symptoms in the first moments after PFS may rarely be the first phase of the biphasic anaphylactic reaction. A slightly longer observation of such patients may prevent later biphasic anaphylaxis.

\section{Informed consent}

Written informed consent was obtained from the patient for publication of this case and any accompanying images.

\section{Conflict of interest}

The authors declared that there are no potential conflicts of interest with respect to the research, authorship, and/or publication of this article.

\section{REFERENCES}

1. Reina L. How to manage complications after sclerotherapy. Small saphenous vein interventional treatment. Phlebolymphology 2017;24:130-43.

2. Rathbun S, Norris A, Stoner J. Efficacy and safety of endovenous foam sclerotherapy: meta-analysis for treatment of venous disorders. Phlebology 2012;27:105-17.

3. Stricker BH, Van Oijen JA, Kroon C, Ovink AH. Anaphylaxis following use of polidocanol. Nederlands tijdschrift voor geneeskunde1990;134:240-2.

4. Eklof B, Rutherford RB, Bergan JJ, Carpentier PH, Gloviczki $\mathrm{P}$, Kistner RL, et al. American Venous Forum International Ad Hoc Committee for Revision of the CEAP Classification: Revision of the CEAP classification for chronic venous disorders: consensus statement. J Vasc Surg 2004;40:1248-52.

5. Tessari L, Cavezzi A, Frullini A. Preliminary experience with a new sclerosing foam in the treatment of varicose veins. Dermatol Surg 2001;27:58-60.

6. Feied CF, Jackson JJ, Bren TS, Bond OB, Fernando CE, Young VC, et al. Allergic reactions to polidocanol for vein sclerosis: two case reports. J Dermatol Surg Oncol 1994;20:466-8. 7. Alqurashi W, Ellis AK. Do corticosteroids prevent biphasic anaphylaxis? J Allergy Clin Immunol Pract 2017;5:1194-205. 8. Oflu AT. [Anaphylaxy]. Kocatepe Med J 2015;16:77-82. [Article in Turkish]

9. Cavezzi A, Parsi K. Complications of foam sclerotherapy. Phlebology 2012;27:46-51.

10. Lee S, Bellolio MF, Hess EP, Erwin P, Murad MH, Campbell RL. Time of onset and predictors of biphasic anaphylactic reactions: a systematic review and meta-analysis. J Allergy Clin Immunol Pract 2015;3:408-16.

11. Çeviker K, Şahinalp Ş, Çiçek E, Demir D, Uysal D, Yazkan $\mathrm{R}$, et al. Quality of life in patients with chronic venous disease in Turkey: influence of different treatment modalities at 6-month follow-up. Qual Life Res 2016;25:1527-36. 